\title{
Fresh Water Anchor Ice Along an Arctic Beach
}

\section{H. ERIC SADLER' ${ }^{1}$ and HAROLD V. SERSON ${ }^{1}$}

Anchor ice is broadly defined in the World Meteorological Organization Sea Ice Nomenclature (WMO 1970) as "submerged ice attached or anchored to the bottom, irrespective of the nature of its formation". We discuss here a form of anchor ice of which we can find no previous description. During August 1978 and 1979 we observed a belt of fresh-water anchor ice along $30 \mathrm{~km}$ of beach between Sheringham Point and Prospect Hills in southwest Cornwallis Island, N.W.T. (Fig. 1). The belt covered about $70 \%$ of the shoreline in 1978 and about $40 \%$ in 1979 ,

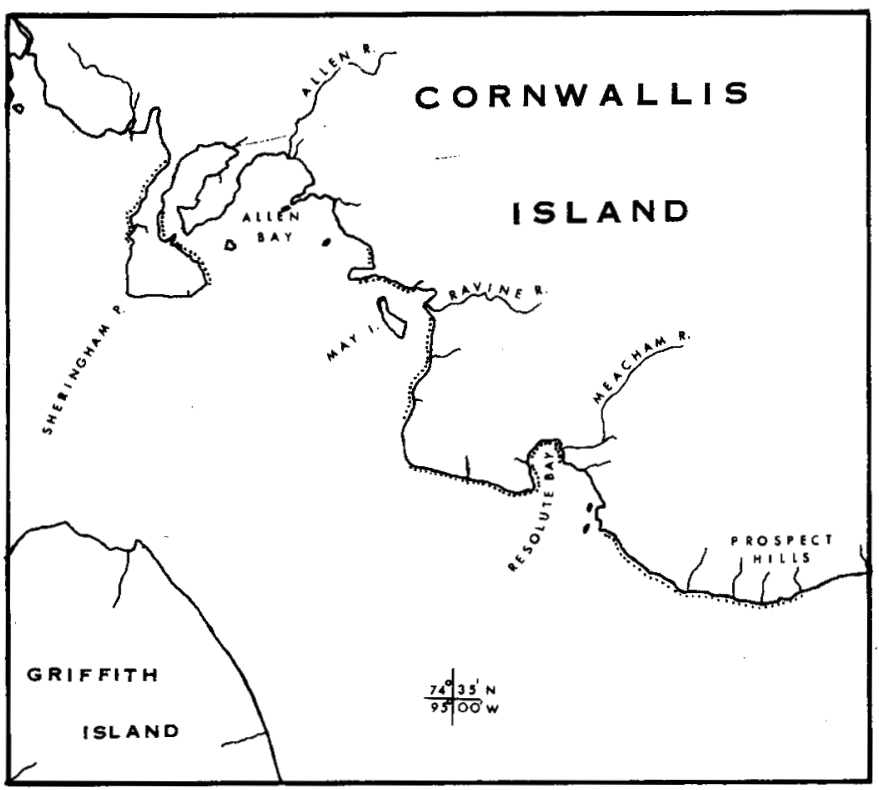

FIG. 1. Location map of beaches examined in 1978 and 1979. Except for a few isolated areas of exposed bed rock in Allen Bay and Resolute Bay, the beaches between Sheringham Point and Prospect Hills are made up of moderately well-sorted gravel which is permeable to run-off water. All rivers and creeks are shown. The dotted lines along the coast indicate beach areas where the anchor belt was essentially continuous.

extending 2-5 $\mathrm{m}$ seawards from the Lower Low Water Springs line and having a typical thickness of $0.5 \mathrm{~m}$ (Fig. 2 ). Where it could be seen, the surface was striated, apparently by gravel frozen into moving ice blocks, but no gravel was found in the body of the fresh-water ice itself. Grounded floes covered part of the belt and in some places there was a thin covering of loose gravel on its upper surface which had been deposited by the melting of ice grounded on top. The lower surface of the anchor ice was continuous with interstitial ice in the undisturbed gravel of of the sea bed. A Sipre auger was used to obtain $7.5 \mathrm{~cm}$ diameter vertical cores through the belt, $2-\mathrm{cm}$ thick samples being cut at $10-\mathrm{cm}$ intervals along the core. After melting in a sealed polythene bag the salinity of the samples was measured using an Endeco refraction salinometer. All of the samples gave values of less than $0.2 \mathrm{ppt}$., much lower than the range of 3-8 ppt. normally found in sea ice, so that the anchor ice could not have been formed bv the freezing of sea water.

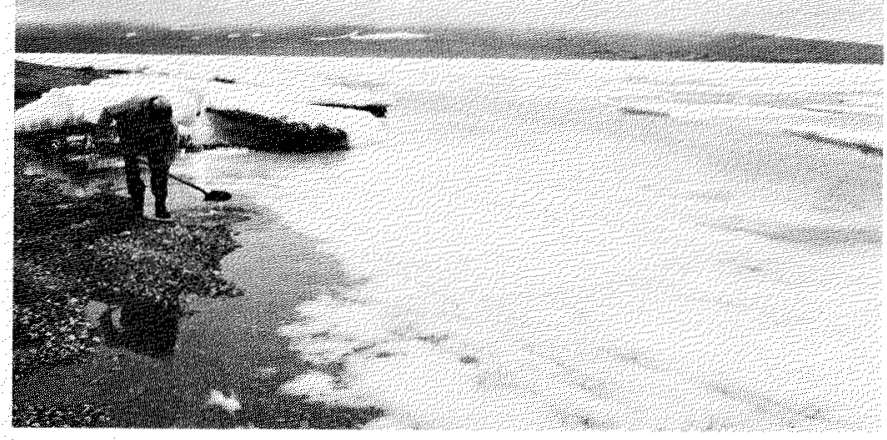

FIG. 2. Fresh water anchor ice along in Resolute Bay, N.W.T. in August, 1978. The photograph was taken at low tide and the water depth over the inner margin of the ice is about $20 \mathrm{~cm}$. The maximum tidal range is $2.0 \mathrm{~m}$ and striations on the surface of the anchor ice are caused by gravel frozen into moving floes. The small blocks of sea ice grounded on the anchor ice are about $1.5 \mathrm{~m}$ thick and have a layer of gravel adhering to the bottom.

The accepted explanation of anchor ice in fresh water streams is that rocks on the stream bed cool by radiation to a clear sky until their temperature falls below freezing point. The skin of ice which forms on the stream bed is usually only two or three cm thick and it is found only in places where the surface is ice free. Such a process does not fit our observations where relatively thick anchor ice occurs beneath a surface cover of sea ice. Anchor ice could also conceivably be formed in the shallow water off the beach when sea ice is forced down onto the sea bed, by ice growth or by piling up, and held there long enough to freeze into place. Subsequent melting of the ice in the upper metre or so might then leave a layer of submerged ice adhering to the bottom, but this ice would have a salinity in the normal range of 3-8 ppt. Joyce (1950) described a dense layer of fragile ice crystals near the bottom below the low water line but he considered that they were carried up into the intertidal zone of the beach by wave swash and consolidated there rather than forming a mass of anchor ice on the sea bed.

The beaches in the study area are made up of moderately well-sorted gravel of which $40 \%$ to $70 \%$ lies between 
$9.5 \mathrm{~mm}$ and $31.5 \mathrm{~mm}$ in maximum dimension with some larger material up to $300 \mathrm{~mm}$. Very little variation exists in the size distribution at six different locations in the area from which a total of 80 samples was taken, except for higher values for the fine fractions (up to $10 \%$ with maximum dimension less than $1 \mathrm{~mm}$ ) in the samples taken from the delta of Ravine River inside May Island. The beaches are generally steeply shelving, rising smoothly to the main storm berm which is typically $1-2 \mathrm{~m}$ above the high water level. In some locations there are flooded areas behind the berm and in several of these we found a similar layer of fresh water anchor ice covering the bottom below half a metre or more of normal sea water. There was also a $50-\mathrm{cm}$ thick layer of fresh-water anchor ice in the mouth of the Meacham river, where the river bed was about $1 \mathrm{~m}$ below low water level.

We suggest that this fresh water anchor ice may be formed from run-off water forced up through the sea bed in the manner shown in Figure 3. During the melt season the gravel above the frost table contains a great deal of water.

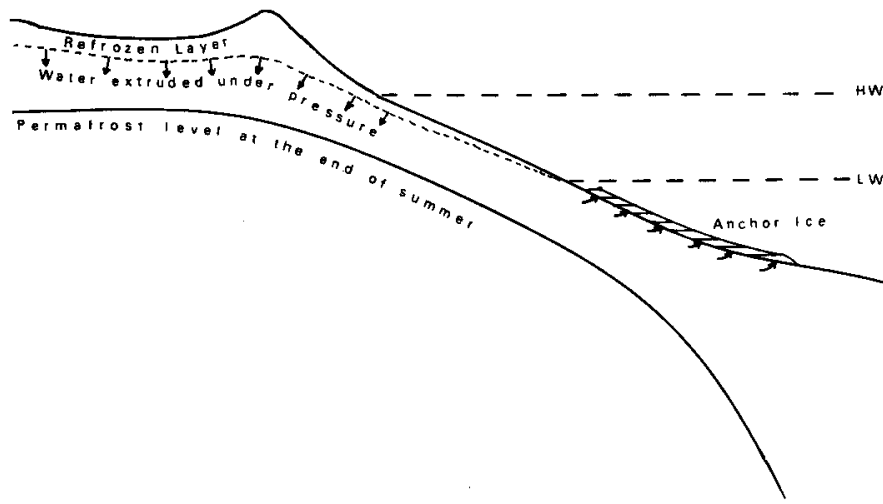

FIG. 3. A model for the formation of anchor ice by migration of ground water. When freezing begins in the fall a duct forms between the permafrost layer below and the surface layer of frozen water in the wet beach gravel. Fresh water passes seaward in the duct under hydrostatic pressure and excess pressure caused by the growing refrozen layer. The depth of the frost table under the beach in the summer of 1978 was between 20 and $30 \mathrm{~cm}$, increasing beyond the low water tide. The vertical scale of the diagram is exaggerated by about $4: 1$.

In July 1978, when most of the annual snow cover melted within a week, so much run-off water was draining through the beach gravel into the sea that the flow was clearly visible. R. L. Nichols (1953) also observed 'a thin sheet of melt water' running over the top of the frozen layer in one of the raised beaches behind the shoreline of Resolute Bay. There are no quantitative data on the volume of this flow but the total run-off through the long stretches of gravel beach may well be comparable to that from all of the seasonal streams and rivers. When colder temperatures return, the surface layer of the wet gravel freezes first, trapping the remaining water in a duct above the frost table. While digging trenches in later August 1978 from the top of the berm to the low water level we found that the depth of the frost table was $20-30 \mathrm{~cm}$ below the surface gravel. These depths are similar to those found by McCann (1971) in Allen Bay in July 1967; the cold spring and the delayed melt season of 1978 could account for this difference. As more of the fresh water freezes, the resulting increase in volume puts pressure on the unfrozen water in the gravel which, combined with the hydrostatic head, forces overcooled fresh water out of the end of the duct and up through the sea bed. Here it meets gravel and sea water at a temperature below $-1{ }^{\circ} \mathrm{C}$ and immediately freezes as the pressure is reduced. The ice sheet may then increase in thickness in one of two ways. The whole sheet might be lifted by the excess pressure of water under it, but in this case we would expect to find gravel incorporated in the ice, or to find the whole sheet breaking free and floating to the surface. Alternatively the fresh water may leak out through cracks in the sheet or around the edges, freezing as it emerges.

The extent of the anchor ice belt is sensitive to a number of factors, primarily the amount of run-off, the length of the run-off period, and the time between the end of the run-off and the first freezing temperatures. In both 1978 and 1979 most of the anchor ice was still present at the beginning of September after freezing had begun at the sea surface, so that some of it must have persisted at least until the next melt season and possibly longer. Because of variations in these factors the extent of the anchor ice probably changes considerably from year to year.

The anchor ice belt may afford significant protection to the sea bed against disturbance by storm-driven ice during the summer and it may have important consequences in regions where ice-push and pile-up are problems because of the reduced friction on the bottom of the moving ice. Because of the increasing industrial use of the beach zone in the Arctic, further investigation of the characteristics of these belts of anchor ice is necessary.

\section{REFERENCES}

JOYCE, J.R.F. 1950. Notes on ice foot development, Neny Fjord, Graham Land, Antarctica. Geological Notes.

McCANN, S.B. and HANNELL, F.G. 1971. Depth of the frost table on arctic beaches, Cornwallis and Devon Islands, N.W.T., Canada. Journal of Glaciology 10(58):155-157.

NICHOLS, R.L. 1953. Geomorphic observations at Thule, Greenland and Resolute Bay, Cornwallis Island, N.W.T. American Journal of Science 251 (April): 268-275.

W.M.O. 1970. Sea Ice Nomenclature. 1970 Edition WMO/OMM/BMO - No. 259. TP 145. Secretariat of the World Meteorological Organization, Geneva, Switzerland. 